\title{
BMJ Open Building patient capacity to participate in care during hospitalisation: a scoping review
}

\author{
Donna Goodridge, ${ }^{\oplus}$ Meghan McDonald, ${ }^{2}$ Lucia New, ${ }^{2}$ Murray Scharf, ${ }^{3}$ \\ Elizabeth Harrison, ${ }^{4}$ Thomas Rotter, ${ }^{5}$ Erin Watson, ${ }^{6}$ Chrysanthus Henry, ${ }^{7}$ \\ Erika D Penz ${ }^{8}$
}

To cite: Goodridge D, McDonald M, New L, et al. Building patient capacity to participate in care during hospitalisation: a scoping review. BMJ Open 2019;9:e026551. doi:10.1136/ bmjopen-2018-026551

- Prepublication history and additional material for this paper are available online. To view please visit the journal (http:// dx.doi.org/10.1136/bmjopen2018-026551).

Received 28 November 2018 Revised 7 June 2019 Accepted 13 June 2019
Check for updates

(C) Author(s) (or their employer(s)) 2019. Re-use permitted under CC BY-NC. No commercial re-use. See rights and permissions. Published by BMJ.

For numbered affiliations see end of article.

Correspondence to Dr Donna Goodridge; donna.goodridge@usask.ca

\section{ABSTRACT}

Objectives To map the existing literature and describe interventions aimed at building the capacity of patients to participate in care during hospitalisation by: (1) describing and categorising the aspects of care targeted by these interventions and (2) identifying the behaviour change techniques (BCTs) used in these interventions. A patient representative participated in all aspects of this project. Design Scoping review.

Data sources MEDLINE, Embase and CINAHL (Inception -2017).

Study selection Studies reporting primary research studies on building the capacity of hospitalised adult patients to participate in care which described or included one or more structured or systematic interventions and described the outcomes for at least the key stakeholder group were included.

Data extraction Title and abstract screening and full text screening were conducted by pairs of trained reviewers. One reviewer extracted data, which were verified by a second reviewer. Interventions were classified according to seven aspects of care relevant to hospital settings. BCTs identified in the articles were assigned through consensus of three reviewers.

Results Database searches yielded a total 9899 articles, resulting in 87 articles that met the inclusion criteria. Interventions directed at building patient capacity to participate in care while hospitalised were categorised as those related to improving: patient safety $(20.9 \%)$; care coordination (5.7\%); effective treatment (5.7\%) and/or patient-centred care using: bedside nursing handovers (5.7\%); communication (29.1\%); care planning (14\%) or the care environment (19.8\%). The majority of studies reported one or more positive outcomes from the defined intervention. Adding new elements (objects) to the environment and restructuring the social and/or physical environment were the most frequently identified BCTs. Conclusions The majority of studies to build capacity for participation in care report one or more positive outcomes, although a more comprehensive analysis is warranted.

\section{INTRODUCTION}

Improving the safety, quality and patient-centredness of care delivered in hospitals is well-recognised as a global priority, ${ }^{12}$ with increasing recognition of the potential of

\section{Strengths and limitations of this study}

- Identification of behaviour change techniques used in included studies highlights the importance of behaviour change as foundational in interventions designed to build hospitalised patient capacity to participate in care.

- Because building capacity of hospitalised patients to participate in care can take many forms, the aims, interventions and study designs included in this review were heterogeneous and largely descriptive.

- Exclusion of grey literature, articles published in languages other than English and articles published after August 2017 are limitations of the study.

- Formal measurement of agreement levels between coders was not performed during the coding training sessions.

Patient focus groups were not included in the scoping review process. Additional patient representatives on this project may have contributed to broader patient perspective.

patient engagement to contribute to the improvement agenda. ${ }^{3}$ Patient engagement is defined by the WHO as the process of building the capacity of patients, families, carers and healthcare providers, in order to enhance safety, quality and patient-centredness of healthcare delivery'. ${ }^{5}$

Effective engagement of patients in care provided during hospitalisation has been associated with better self-management, ${ }^{67}$ fewer adverse events ${ }^{8}$ and diagnostic tests, ${ }^{9}$ decreased use of health services ${ }^{10}$ and shorter lengths of stay. ${ }^{11}$ Patients and families who are engaged in care have opportunities to provide information essential to appropriate care planning, ${ }^{12}$ to recognise errors in care delivery ${ }^{13}$ and to adhere to treatment plans. ${ }^{14}$ Additional benefits of effective patient and family engagement include: enhancing system responsiveness to evolving user needs ${ }^{15}$ promoting decision-making 
transparency and improving quality ${ }^{1617}$ and reducing cost and waste. ${ }^{15}$

The quality challenges common to healthcare systems include the need to improve patient safety, patient-centred care, coordination of care, effective prevention and treatment, healthy living and care affordability. ${ }^{18}$ Within hospital settings, high acuity and rapid patient turnover represent barriers to effective patient participation in care to an extent not found in other healthcare settings. Wide variability in the implementation of practices designed to promote patient and family engagement was identified in a survey of US hospitals. ${ }^{17}$ These practices were classified into the following categories: (1) organisational (eg, formal policy for disclosing medical error); (2) bedside (eg, participation in shift change report) and (3) access to information and shared decision-making (eg, online access to personal health information).

Better understanding of the characteristics of interventions aimed at building the capacity of hospitalised patients to participate in care is important for building the evidence base in this area and strengthening the theoretical underpinnings of future interventions at the design phase. Successful implementation of these types of interventions may be facilitated by the incorporation of systematic methods such as behaviour change techniques (BCTs) for characterising interventions and linking these to an analysis of the targeted behaviour. ${ }^{19} 20$ BCTs are defined as 'observable, replicable and irreducible component(s) [s] of an intervention designed to alter or redirect causal processes that regulate behaviour. ${ }^{19}$ The BCT Taxonomy can offer a reliable and systematic framework for the identification of the 'active, effective' components within specific interventions, ${ }^{19}$ provided sufficient detail is provided about the intervention. ${ }^{21}$

Given the dynamic state of evidence describing interventions to promote patient participation, a scoping review was the most appropriate method to produce a narrative integration of relevant evidence addressing our broadly defined question. ${ }^{21}$ Although efforts to intentionally build capacity to participate in care have become a priority in many hospitals, much remains to be learnt about how to best accomplish this goal. In order to advance the evidence base in this area, this scoping review aimed to map the existing literature and describe interventions aimed at building the capacity of patients to participate in care during hospitalisation. Our specific research questions were to: (1) describe and categorise the aspects of care targeted by these interventions and (2) identify the BCTs used in the interventions to build patient participation in care.

\section{METHODS}

\section{Design}

As one form of knowledge synthesis, scoping reviews provide narrative integration of relevant evidence by mapping key concepts, types of evidence and gaps in research to address a broad question investigating a particular field. ${ }^{22}$ To date, there have been no syntheses of the interventions designed to build capacity of hospitalised patients to participate in care. The original protocol for this review was published in 2018. ${ }^{23}$

This systematic scoping review has allowed us to determine the extent, range and nature of research activity related to initiatives designed to build the capacity of hospitalised patients to participate in care. Guided by the methodology proposed by Arksey and O'Malley ${ }^{22}$ and its subsequent revisions, ${ }^{24}{ }^{25}$ this review included the following steps: (1) identifying the research question; (2) identifying relevant studies; (2) describing study selection criteria; (3) charting the data and (3) collating, summarising and reporting the results. In keeping with other scoping reviews in which the research team is large and multidisciplinary, ${ }^{26}$ we did not undertake the optional step of consultation. To further outline the methodology, a completed PRISMA-SCr Checklist ${ }^{27}$ for scoping reviews has been attached. Because scoping reviews seek to understand topics of significant complexity in a broad area, rather than synthesise only the best available evidence, a quality appraisal of included studies was not performed. ${ }^{22}$

\section{Patient and public involvement}

A patient who was also a retired university professor (MS) with an education background was a member of the research team. He was recruited to provide a patient's perspective. ${ }^{28}$ The lack of patient focus groups is recognised as a limitation of the study; however, the patient representative contributed actively to all phases of the scoping review from inception. He shared his experiences within the system and contributed to interpretation of the findings. We did not include patient focus groups in the consultation process for this scoping review.

\section{Identifying the research question}

In collaboration with knowledge users from the provincial Health Quality Council and health region in Saskatchewan, Canada, as well as decision makers from the Saskatchewan Ministry of Health, the team identified the following question as the focus for this scoping review: What are the characteristics of interventions designed to build the capacity of hospitalised patients in addressing key healthcare priorities reported in the literature?

\section{Identifying relevant studies}

Following an initial scan of potentially relevant databases (including the Cochrane Database of Systematic Reviews), MEDLINE, Embase and CINAHL were selected for use in this review as having the best coverage of literature related to hospitals. A comprehensive electronic literature search was conducted by an experienced medical librarian (EW) in MEDLINE (through OVID), Embase (through OVID) and CINAHL Plus (through EBSCOhost) from inception to 15 December 2016 and updated on 31 August 2017. Our search strategy included the following key terms and synonyms: acute care; hospitals; caregivers; family and patient participation, empowerment, engagement 
or involvement. Please see online supplementary file 1 for the comprehensive search strategy in MEDLINE. The reference lists of studies were examined to identify additional relevant articles.

Literature search results were uploaded into Covidence Systematic Review Software ${ }^{29}$ after removing duplicate references. This software provides a decision dashboard and annotation tool as well as the capacity to create forms for screening and extracting data. Additional duplicates missed by the reference software were removed as identified. Studies were selected in two phases: (1) title and abstract screening and (2) full text screening/review.

\section{Study selection}

Inclusion and exclusion criteria were developed based on a preliminary literature review and the advice of knowledge users and decision-makers. In order to be included in this scoping review, the studies must have: (1) taken place within a hospital setting (including inpatient rehabilitation); (2) described or included a structured or systematic approach to building capacity of patients to participate in care, including organisational practices, bedside practices or access to information practices; (3) included adult patients only and (4) described the outcomes of the interventions from any one of the following stakeholder perspectives: patients and families; healthcare providers; health systems or administrators/ funders. All study designs were included, provided that the studies adhered to the inclusion/exclusion criteria. We included only studies published in English for this scoping review, as this was the primary language spoken by team members.

Papers addressing interventions to build capacity in the following populations were excluded: children and adolescents; community or home settings; oncology patients (because this group often experiences rapid transitions between community, outpatient and inpatient settings) and emergency department settings. We also excluded papers focused on patient participation in research, databases, quality improvement (eg, patient advisory councils) or healthcare service redesign or patient needs, knowledge or activation assessments.

Team training sessions for reviewers consisted of group screening of 20 titles. The inclusion and exclusion criteria were pilot-tested during the training session resulting in minor revisions to enhance the clarity of descriptors and improve inter-rater reliability. Following this training, titles and abstracts were screened by two reviewers, one of whom was the PI (DG) ${ }^{26}$ Discrepancies were resolved through consensus between the reviewers.

A second team training session for full text screening and review was held. Eight of the nine team members participated in full text screening and review, with EP serving as an arbitrator. Two researchers independently reviewed each of articles selected for full-text screening to ensure inclusion criteria had been met. Discrepancies were discussed between the researchers to achieve consensus and in one case, the dispute was resolved by the arbitrator.

\section{Charting the data}

A standard data extraction form created using Microsoft Word (online supplementary file 2) was pilot-tested in the team training session prior to data extraction. Use of this software, rather than the preset categories in Covidence, allowed us flexibility in data extraction categories and entries. Pairs of team members were randomly assigned to extract data from 20 articles. Key characteristics extracted by the two reviewers for each article included: (1) study identification (author, year of publication, setting, country); (2) focus of the intervention; (3) description of the intervention; (4) study design and participants and (5) study findings. All extracted data from each pair of team members were reviewed and confirmed by DG.

In order to categorise the focus of each article, reviewers initially coded each article according to the terms used by the authors (eg, multidisciplinary goal setting). Two team members (DG and $\mathrm{CH}$ ) then assigned each article to one of seven categories adapted from the AHRQ National Quality Strategy Priorities ${ }^{18}$ that reflected dominant themes of this corpus of literature: patient safety; care coordination; effective treatment; bedside nursing handovers; communication; care planning and the care environment.

Coding of BCT categories and techniques occurred following the data extraction. Each article was re-read by DG, MM and LN. BCT codes were assigned independently using the operational definitions provided by the BCT taxonomy $1^{19}$ and the supplementary BCT coding framework reported by Presseau $e t a .^{21}$ There was no limit on the number of BCTs that could be identified. Discrepancies in BCT assignment were discussed and consensus achieved.

\section{Collating, summarising and reporting the results}

A narrative approach was used to collate, summarise and report the data. Summary statistics were used to describe the number of studies by setting, country, year of publication, methods, focus and BCTs identified.

\section{RESULTS}

A total of 9899 articles (9239 on 15 December 2016 and 660 in the search update on 31 August 2017) were identified after duplicates were removed through the search process (figure 1). Following title and abstract screening, 503 remaining articles met our inclusion criteria and underwent full-text screening. During the full-text assessment, 416 were excluded because they did not meet one or more of the eligibility criteria $(n=319)$, did not report on a specific intervention $(n=36)$ or were conference abstracts $(n=61)$. See figure 1 for the PRISMA flow diagram.

\section{Characteristics of included studies}

Online supplementary file 3 presents the summary of included studies $(\mathrm{n}=87) \cdot{ }^{30-117}$ Over half of these studies 


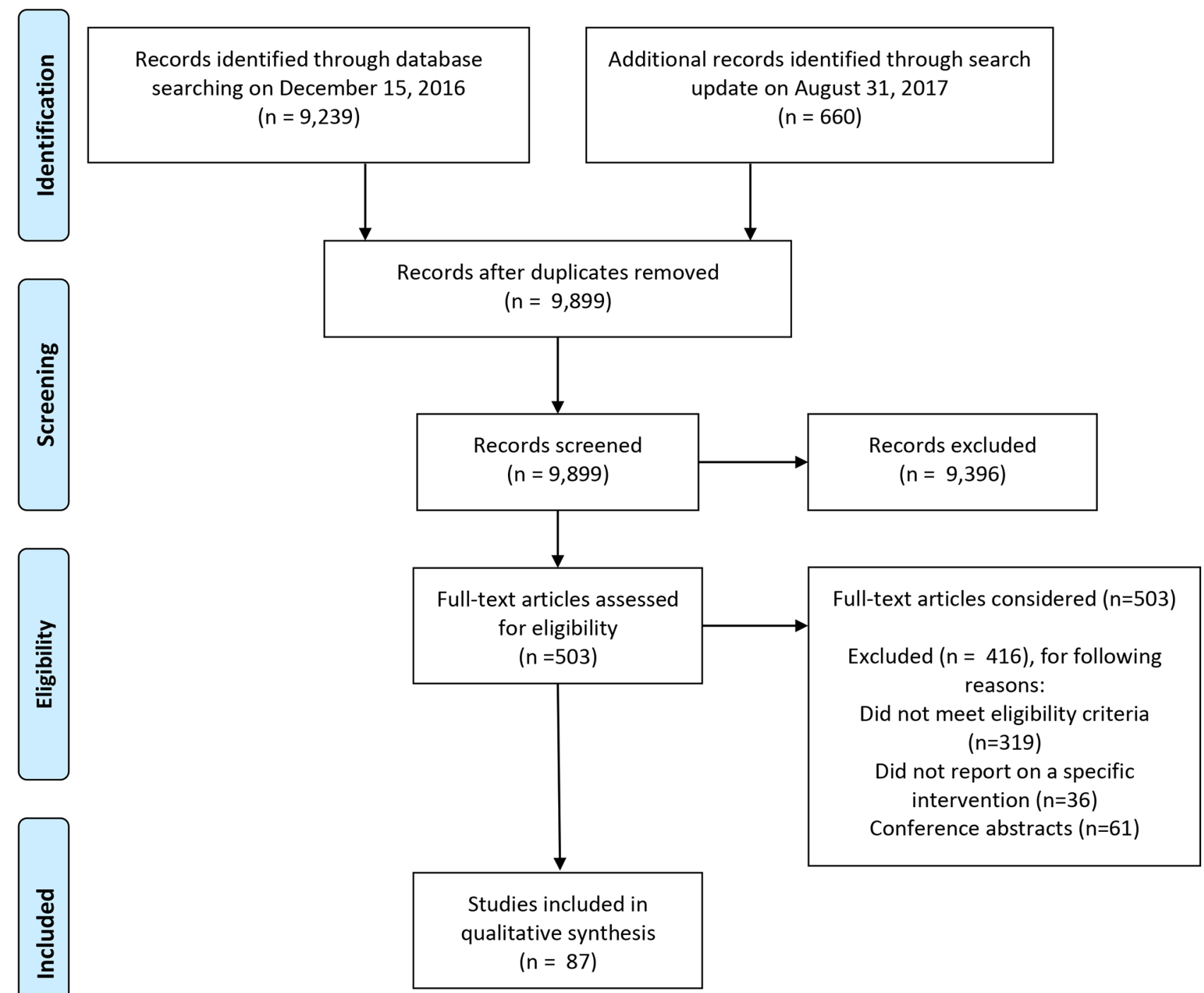

From: Moher D, Liberati A, Tetzlaff J, Altman DG, The PRISMA Group (2009). Preferred Reporting /tems for Systematic Reviews and MetaAnalyses: The PRISMA Statement. PLoS Med 6(7): e1000097. doi:10.1371/journal.pmed1000097

Figure 1 PRISMA screening flowchart.

originated in either the USA $(n=32,36.8 \%)$ or the UK $(\mathrm{n}=17,19.5 \%)$. Fifteen $(17.2 \%)$ came from Scandinavian countries and eight from Australia (9.2\%). Only five $(5.7 \%)$ articles were published prior to 2000 .

\section{Study designs}

The studies included were methodologically diverse. Of the 87 included articles, three $(3.4 \%)$ were randomised controlled trials examining outcomes of interventions designed to build patient capacity to participate in care coordination, ${ }^{40}$ communication $^{66}$ and effective treatment. ${ }^{109}$ Three $(3.4 \%)$ cluster randomised controlled trials were aimed at improving patient capacity to participate in safety initiatives, ${ }^{82}$ recognise deteriorating condition ${ }^{106}$ and the care environment. ${ }^{115}$

The remaining studies included quasiexperimental designs, case-controlled studies (including the use of administrative data), interrupted time series, ethnographies, case studies, chart reviews and pretest and posttest designs. Qualitative and mixed methods approaches $(\mathrm{n}=29,33.3 \%)$ and cross-sectional or preinterventions and postinterventions surveys $(n=21,24.1 \%)$ were used in over half of the included studies.

\section{Patient populations}

While a significant proportion of capacity-building interventions (eg, safety, rapid response teams) were implemented across entire acute care hospitals, other studies were directed towards specific patient populations, such as critically ill $(\mathrm{n}=7,8.0 \%), 355671738597$ geriatric $(n=6,6.9 \%), 53788692103113$ rehabilitation $(n=9$, $10.3 \%),^{4869708997104108116117}$ surgical $(\mathrm{n}=6,6.9 \%)^{6472109112113}$ or psychiatric $(\mathrm{n}=8,9.2 \%)^{3458688795100101110}$ patients. 


\section{Outcomes}

Positive outcomes were reported in two of the three randomised controlled trials ${ }^{4068}$ and two of the three cluster randomised controlled trials. ${ }^{106} 115$ Failure to achieve key study objectives were reported in a number of the remaining studies. ${ }^{33} 507782858796100112$ The remaining studies reported one or more positive outcomes associated with the intervention to build hospitalised patient capacity to engage in care.

\section{Aspects of care addressed by capacity-building interventions} Interventions designed to build patients' capacity to participate were found to address seven key aspects of care in hospitals. These aspects of care included: patient safety $(n=18 ; 20.7 \%)$; bedside nursing handovers $(n=5$; $5.7 \%)$; communication $(\mathrm{n}=25 ; 28.7 \%)$; care planning $(\mathrm{n}=12 ; 13.8 \%)$; modifications to the care environment to promote engagement $(n=17 ; 19.5 \%)$; care coordination $(n=5 ; 5.7 \%)$ and effective treatment $(5 ; 5.7 \%)$.

The interventions focused on patient safety addressed a range of safety issues including: medications; ${ }^{30} 396077114$ falls; $^{30} 5369$ hand-washing; ${ }^{30} 4647548490$ surgical site identification; ${ }^{30}$ medical error ${ }^{80}$ or patient reporting and action. ${ }^{32} 7782889398$ Eleven (12.6\%) studies incorporated a form of information technology to build the capacity of patients to participate in care.

One-third of the included studies $(n=25 ; 28.7 \%)$ reported interventions designed to enhance communication between patients and providers to promote participation in care. Examples included interventions designed to encourage interactions between patients, families and providers, ${ }^{35445271}$ to provide a means by which patients or families could communicate their wishes or concerns ${ }^{74758185}$ or to share clinical information with patients. $^{3361667297}$

Multicomponent programmes aimed at enhancing the environment in which patient-and family-care was delivered accounted for $17(19.5 \%)$ studies. These interventions often involved new models of care specifically aimed at promoting patient-centredness using multiple interventions, such as the adoption of new standards of care. ${ }^{79}$

\section{Behaviour change techniques identified to build patient capacity to participate in care}

Table 1 describes the types of BCTs used to build capacity for each of the seven key aspects of care.

Overall, the use of antecedents was the most frequently identified category of BCT $(n=76,87.3 \%)$. This category includes: restructuring the physical environment; restructuring the social environment; avoidance/reducing exposure to cues for the behaviour; distraction; adding objects to the environment and body changes (eg, strength training). ${ }^{19}$ Antecedents can be used to 'set the stage' for desired responses. Because of the frequency of identification of the category of antecedents, this category of BCT was further coded into the specific techniques employed. Adding objects to the environment was identified as an antecedent in a total of $48(55.2 \%)$ studies. Examples of adding objects to promote patient participation in care included the use of instructional videos, for example, Refs. 62, 99 and introduction of technologies such as tablets to share information. ${ }^{31}$ Fifteen $(17.2 \%)$ of these studies simultaneously added objects in conjunction with restructuring the social environment. This is illustrated by Dykes et al's ${ }^{55}$ multifaceted intervention involving a patient-centred care and engagement programme and web-based technology, including a safety checklist and a messaging platform used by patients and care partners to view health information, participate in their care plan and communicate with care providers.

Studies that changed the social environment $(n=41$, $47.1 \%$ ) to facilitate patient participation in care were classified as having employed the BCT of restructuring the social environment (BCT). Following the BCT coding rules of Presseau et $a l,{ }^{21}$ we included in this category studies which described interventions in which someone new (patients, family member or provider) took on care, someone was added to take on new care responsibilities or someone was added to the team or care was shifted outside the team. An example of changes made to the social environment was the adoption of a new model of care providing flexible family visiting, supporting carer involvement and improving partnerships between carers and the healthcare team. ${ }^{59}$

Five studies $(5.7 \%)$ were identified as making simultaneous changes to both the social and physical environments. An instance of changing both the social and physical environment was reported by Rise et $a l,{ }^{100}$ who established a new patient education centre as one component of an intervention, along with appointing staff who could be contacted by families. No studies were identified as restructuring only the physical environment.

Shaping knowledge was identified as a BCT in 33 studies $(37.9 \%)$. This BCT is illustrated in the study by Langer $e t a l^{80}$ in which clinicians were brought together with patients and families in a collaborative learning experience focused on developing patient-centred medical error disclosure communication skills. A second example of shaping knowledge was the use of the PINK (Participate; Be informed; Notice and be alert; Know what you can do) video ${ }^{46}$ with the specific goal of educating patients in the prevention of medical errors.

Feedback and monitoring were identified in 20 studies $(23.0 \%)$. An example is Coleman et al $\mathrm{s}^{40}$ Care Transition programme, in which patients monitored and responded to changes in their health conditions as a component of the intervention. Goals and planning were coded in 19 studies $(21.8 \%)$. An example of goals and planning involved goal setting meetings between the patient, family and multidisciplinary team. ${ }^{43}$ Other categories of BCTs identified in the studies included: social support $(n=7$; $8.0 \%)$; repetition and substitution $(n=5 ; 5.7 \%)$; regulation $(n=4 ; 4.6 \%)$; natural consequences $(n=3 ; 3.4 \%)$ and comparison of behaviour $(n=2 ; 2.3 \%)$. The BCTs of association, identity and scheduled consequences were identified in one study each. Categories of BCT not identified 
Table 1 BCTs identified to build patient capacity to participate in care $(n=87)$

\begin{tabular}{|c|c|c|}
\hline Aspect of care & References & ВCT \\
\hline \multirow[t]{12}{*}{ Patient safety $(n=18)$} & 30 & $\begin{array}{l}\text { Shaping knowledge } \\
\text { Antecedents (adding objects to the environment) }\end{array}$ \\
\hline & 32 & $\begin{array}{l}\text { Antecedents (restructuring the physical and social environment; adding objects to } \\
\text { the environment) }\end{array}$ \\
\hline & $39^{*}$ & Antecedents (adding objects to the environment) \\
\hline & 46 & $\begin{array}{l}\text { Shaping knowledge } \\
\text { Antecedents (adding objects to the environment) }\end{array}$ \\
\hline & $53^{*}$ & Antecedents (adding objects to the environment) \\
\hline & 54 & $\begin{array}{l}\text { Shaping knowledge } \\
\text { Antecedents (adding objects to the environment) }\end{array}$ \\
\hline & 60 & Antecedents (adding objects to the environment) \\
\hline & 80 & $\begin{array}{l}\text { Antecedents (restructuring social environment) } \\
\text { Shaping knowledge } \\
\text { Repetition and substitution } \\
\text { Comparison of behaviour (demonstration) }\end{array}$ \\
\hline & 82 & $\begin{array}{l}\text { Antecedents (adding objects to the environment) } \\
\text { Feedback and monitoring }\end{array}$ \\
\hline & 84 & $\begin{array}{l}\text { Antecedents (adding objects to the environment) } \\
\text { Feedback and monitoring } \\
\text { Association (prompts and cues) }\end{array}$ \\
\hline & 88 & $\begin{array}{l}\text { Antecedents (adding objects) } \\
\text { Feedback and monitoring }\end{array}$ \\
\hline & 114 & Antecedents (restructuring the social environment) \\
\hline \multirow[t]{5}{*}{$\begin{array}{l}\text { Person-centred and family-centred care: } \\
\text { Bedside nursing handovers }(n=5)\end{array}$} & 31 & $\begin{array}{l}\text { Shaping knowledge } \\
\text { Antecedents (adding objects to the environment) }\end{array}$ \\
\hline & 37 & $\begin{array}{l}\text { Antecedents (restructuring the physical and social environments) } \\
\text { Scheduled consequences }\end{array}$ \\
\hline & 76 & Antecedents (restructuring the social environment) \\
\hline & 91 & Antecedents (restructuring social environment) \\
\hline & 105 & $\begin{array}{l}\text { Shaping knowledge } \\
\text { Antecedents (restructuring social environment; adding objects to the environment) }\end{array}$ \\
\hline \multirow{7}{*}{$\begin{array}{l}\text { Person-centred and family-centred care: } \\
\text { Communication }(n=25)\end{array}$} & $33^{*}$ & Antecedents (adding objects to the environment) \\
\hline & 35 & $\begin{array}{l}\text { Shaping knowledge } \\
\text { Social support }\end{array}$ \\
\hline & $44^{*}$ & $\begin{array}{l}\text { Goals and planning } \\
\text { Antecedents (restructuring the social environment; adding objects to the } \\
\text { environment) }\end{array}$ \\
\hline & 48 & Goals and planning \\
\hline & 50 & $\begin{array}{l}\text { Feedback and monitoring } \\
\text { Antecedents (adding objects to the environment) }\end{array}$ \\
\hline & 52 & Antecedents (restructuring social environment) \\
\hline & $55^{*}$ & $\begin{array}{l}\text { Antecedents (restructuring the social environment; adding objects to the } \\
\text { environment) }\end{array}$ \\
\hline
\end{tabular}

Continued 
Table 1 Continued

\begin{tabular}{|c|c|c|}
\hline Aspect of care & References & BCT \\
\hline & $61^{*}$ & $\begin{array}{l}\text { Antecedents (restructuring the social environment; adding objects to the } \\
\text { environment) }\end{array}$ \\
\hline & 62 & $\begin{array}{l}\text { Shaping knowledge } \\
\text { Antecedents (adding objects to the environment) }\end{array}$ \\
\hline & $63^{*}$ & Antecedents (adding objects to the environment) \\
\hline & 65 & $\begin{array}{l}\text { Feedback and monitoring } \\
\text { Antecedents (restructuring social environment; adding objects to the environment) }\end{array}$ \\
\hline & $66^{*}$ & $\begin{array}{l}\text { Antecedents (adding objects to the environment) } \\
\text { Shaping knowledge } \\
\text { Feedback and monitoring }\end{array}$ \\
\hline & 68 & $\begin{array}{l}\text { Shaping knowledge } \\
\text { Repetition and substitution (behavioural practice) } \\
\text { Feedback and monitoring }\end{array}$ \\
\hline & 71 & $\begin{array}{l}\text { Shaping knowledge } \\
\text { Antecedents (restructuring the social environment; adding objects to the } \\
\text { environment) }\end{array}$ \\
\hline & 72 & $\begin{array}{l}\text { Shaping knowledge } \\
\text { Antecedents (adding objects to the environment) }\end{array}$ \\
\hline & 74 & $\begin{array}{l}\text { Feedback and monitoring } \\
\text { Antecedents (restructuring the social environment; adding objects to the } \\
\text { environment) }\end{array}$ \\
\hline & 75 & $\begin{array}{l}\text { Feedback and monitoring } \\
\text { Antecedents (restructuring the social environment; adding objects to the } \\
\text { environment) }\end{array}$ \\
\hline & 81 & $\begin{array}{l}\text { Goals and planning } \\
\text { Antecedents (adding objects to the environment) }\end{array}$ \\
\hline & 85 & $\begin{array}{l}\text { Shaping knowledge } \\
\text { Antecedents (restructuring the social environment) }\end{array}$ \\
\hline & 86 & Antecedents (restructuring the social environment) \\
\hline & $94^{*}$ & $\begin{array}{l}\text { Shaping knowledge } \\
\text { Antecedents (adding objects to the environment) }\end{array}$ \\
\hline & 97 & $\begin{array}{l}\text { Shaping knowledge } \\
\text { Antecedents (restructuring the social environment; adding objects to the } \\
\text { environment) }\end{array}$ \\
\hline & 103 & $\begin{array}{l}\text { Shaping knowledge } \\
\text { Antecedents (adding objects to the environment) } \\
\text { Goals and planning } \\
\text { Feedback and monitoring }\end{array}$ \\
\hline & 107 & $\begin{array}{l}\text { Antecedents (adding objects to the environment) } \\
\text { Goals and planning }\end{array}$ \\
\hline & 110 & Antecedents (restructuring the social environment) \\
\hline \multirow[t]{9}{*}{$\begin{array}{l}\text { Person-centred and family-centred care: } \\
\text { Care planning }(n=12)\end{array}$} & $42^{*}$ & $\begin{array}{l}\text { Feedback and monitoring } \\
\text { Antecedents (adding objects to the environment) }\end{array}$ \\
\hline & 45 & $\begin{array}{l}\text { Goals and planning } \\
\text { Antecedents (restructuring the social environment) }\end{array}$ \\
\hline & 49 & $\begin{array}{l}\text { Goals and planning } \\
\text { Antecedents (restructuring the social environment) }\end{array}$ \\
\hline & 51 & Goals and planning \\
\hline & $56^{*}$ & Antecedents (adding objects to the environment) \\
\hline & 73 & Antecedents (restructuring the social environment) \\
\hline & 96 & Antecedents (restructuring the social environment) \\
\hline & 102 & Antecedents (restructuring the social environment) \\
\hline & 111 & $\begin{array}{l}\text { Antecedents (restructuring the social environment) } \\
\text { Goals and planning }\end{array}$ \\
\hline
\end{tabular}

Continued 
Table 1 Continued

\begin{tabular}{|c|c|c|}
\hline Aspect of care & References & BCT \\
\hline & 112 & $\begin{array}{l}\text { Antecedents (restructuring the social environment) } \\
\text { Feedback and monitoring }\end{array}$ \\
\hline & 116 & $\begin{array}{l}\text { Goals and planning } \\
\text { Antecedents (restructuring the social environment) }\end{array}$ \\
\hline & 117 & $\begin{array}{l}\text { Goals and planning } \\
\text { Antecedents (restructuring the social environment) } \\
\text { Social support }\end{array}$ \\
\hline \multirow{10}{*}{$\begin{array}{l}\text { Person-centred and family- centred care: } \\
\text { Care environment programmes }(n=17)\end{array}$} & 36 & $\begin{array}{l}\text { Goals and planning } \\
\text { Feedback and monitoring } \\
\text { Antecedents (restructuring the physical and social environments) }\end{array}$ \\
\hline & 58 & $\begin{array}{l}\text { Feedback and monitoring (self-monitoring of behaviour) } \\
\text { Antecedents (restructuring the social environment) }\end{array}$ \\
\hline & 67 & $\begin{array}{l}\text { Social support } \\
\text { Antecedents (restructuring the social environment) }\end{array}$ \\
\hline & 78 & $\begin{array}{l}\text { Shaping knowledge } \\
\text { Antecedents (adding objects to the environment) } \\
\text { Social support }\end{array}$ \\
\hline & 79 & $\begin{array}{l}\text { Antecedents (restructuring the social environment; adding objects to the } \\
\text { environment) } \\
\text { Goals and planning }\end{array}$ \\
\hline & 87 & $\begin{array}{l}\text { Social support } \\
\text { Antecedents (restructuring the social environment) }\end{array}$ \\
\hline & 104 & $\begin{array}{l}\text { Goals and planning } \\
\text { Antecedents (restructuring the social environment; adding objects to the } \\
\text { environment) }\end{array}$ \\
\hline & 108 & Antecedents (restructuring the social environment) \\
\hline & 113 & $\begin{array}{l}\text { Shaping knowledge } \\
\text { Antecedents (restructuring the social environment) }\end{array}$ \\
\hline & 115 & $\begin{array}{l}\text { Shaping knowledge } \\
\text { Feedback and monitoring }\end{array}$ \\
\hline \multirow[t]{5}{*}{ Care coordination $(n=5)$} & 38 & $\begin{array}{l}\text { Shaping knowledge } \\
\text { Antecedents (adding objects to the environment) }\end{array}$ \\
\hline & 40 & $\begin{array}{l}\text { Shaping knowledge } \\
\text { Antecedents (adding objects to the environment) } \\
\text { Feedback and monitoring } \\
\text { Natural consequences } \\
\text { Goals and planning }\end{array}$ \\
\hline & 41 & $\begin{array}{l}\text { Shaping knowledge } \\
\text { Antecedents (adding objects to the environment) } \\
\text { Natural consequences } \\
\text { Goals and planning }\end{array}$ \\
\hline & 43 & $\begin{array}{l}\text { Antecedents (adding objects to the environment) } \\
\text { Regulation }\end{array}$ \\
\hline & 57 & $\begin{array}{l}\text { Shaping knowledge } \\
\text { Identity }\end{array}$ \\
\hline
\end{tabular}


Table 1 Continued

\begin{tabular}{lll}
\hline Aspect of care & References & BCT \\
\hline $\begin{array}{l}\text { Effective treatment } \\
(n=5)\end{array}$ & 70 & $\begin{array}{l}\text { Shaping knowledge } \\
\text { Feedback and monitoring } \\
\text { Repetition and substitution } \\
\text { Regulation }\end{array}$ \\
& 83 & $\begin{array}{l}\text { Antecedents (restructuring the social environment; adding objects to the } \\
\text { environment) } \\
\text { Goals and planning } \\
\text { Repetition and substitution } \\
\text { Regulation }\end{array}$ \\
& $\begin{array}{l}\text { Antecedents (adding objects to the environment) } \\
\text { Feedback and monitoring } \\
\text { Shaping knowledge }\end{array}$ \\
& $\begin{array}{l}\text { Shaping knowledge } \\
\text { Antecedents (restructuring the social environment; adding objects to the } \\
\text { environment) } \\
\text { Antecedents (restructuring the social environment) } \\
\text { Social support } \\
\text { Regulation }\end{array}$ \\
& 106 & \\
& 109 &
\end{tabular}

*Studies that included some information technology used by patients and/or families.

BCTs, behaviour change techniques.

in any of the included studies were reward and threat, self-belief and covert learning.

In the majority of studies $(\mathrm{n}=69 ; 79.3 \%)$, the use of multiple categories of BCT as part of the capacity-building intervention could be identified. In studies where only a single BCT was identified, restructuring the social environment $t^{52} 737686919699101108110$ occurred most frequently $(n=10)$, although adding objects to the environment, ${ }^{33} 3953566063$ and goals and planning ${ }^{4851}$ were also employed as BCTs.

\section{DISCUSSION AND CONCLUSION}

This scoping review has identified seven aspects of care in which efforts to build capacity of hospitalised patients to participate in care were reported: patient safety; care coordination; effective treatment; bedside nursing handovers; communication between patients and providers; inpatient care planning; and the overall care environment. Both largescale (hospital-wide) and population-specific and unit-specific interventions were reported. Descriptions of these interventions in the included studies provided sufficient detail to allow for classification of the key BCTs used within each intervention. The use of antecedents (eg, adding objects to the environment or restructuring the social and/ or physical environment) was the most frequently identified BCT category across all included studies. In $60 \%$ of the studies, multiple BCTs could be identified.

In keeping with the nature of a scoping review, the articles included in this scoping review were heterogeneous in terms of the aspect of care addressed, aims and methodological rigour. The strength of evidence was generally weak to very weak, thus limiting the interpretation and application for wider clinical practice. This heterogeneity limited our ability to draw conclusions about the effectiveness of the interventions. Quality appraisal was not undertaken and, as previously identified, articles were limited to English language only and did not include grey literature. Specific details of interventions were not always provided in the publications and it is possible that some BCTs used could not be accurately identified by the three reviewers who classified and achieved consensus on the BCTs identified. While our search strategy was limited to MEDLINE, Embase and CINAHL, it would be helpful to consider the inclusion of additional databases in future reviews. Although we searched the Cochrane database and did not find relevant systematic reviews, new reviews may be available in the future. As research addressing patient participation in care becomes increasingly more sophisticated, future reviews may focus on specific aspects of care such as safety for defined groups of patients.

Reviews are increasingly seeking to identify the BCTs used in a range of interventions ${ }^{118-120}$ in order to better understand the content of interventions and the underlying reasons for the outcomes associated with interventions. Adding objects to the environment was identified as the most frequently used BCT intervention in this scoping review, in keeping with the findings of Presseau et al..$^{21}$ Depending on the nature of the publication and the intervention, more detailed descriptions of interventions were available for some studies compared with others. Attempts to build capacity for patients to participate in care are, at their core, social in nature and particular care should be taken to describe how the social environment facilitates performance of the desired behaviour or creates barriers to behaviours excluding patients or families from participation.

Interventions aimed at building the capacity of hospitalised patients to participate more fully in care require the use of complex interventions, especially as patient behaviour cannot change independently of provider behaviour and healthcare system attributes. Genuine engagement of patients in care will require a realignment of long-standing 
power imbalances between patients, providers and the healthcare system, resulting in significant changes in behaviour at many levels. ${ }^{121}$ The participation of a patient representative on this team examining the issue of patient participation proved to be extremely helpful. This individual participated in all aspects of this review, from defining the research question, screening and selection of included studies and data extraction. He provided key insights into the interpretation of the results from the perspective of an end user of the healthcare system. This individual reported that participation in this process gave him a sense of empowerment that he was influencing the knowledge base of patient care. He also noted that the process provided him with knowledge to better critique the delivery of health services. The recent GRIPP2 reporting checklist on improving the reporting of patient and public involvement in research ${ }^{26}$ provides important guidance on this issue. We would recommend that future studies include patient focus groups as a means of expanding patient input.

The rapidly evolving interest in developing interventions promoting the participation of hospitalised patients in care was demonstrated by the additional 660 articles that were published over the 8 month period between the time of the initial search and the search update. Given the growing corpus of research, this review provides an important synthesis of what has been reported to build the capacity of hospitalised patients to participate in care. This review aimed also to classify the 'active ingredients' underpinning the interventions by using the BCT Taxonomy. ${ }^{19}$ The findings generated through this synthesis will provide an evidentiary basis for the development of, and future research related to, tailored approaches to building patient capacity to participate in care.

\section{Author affiliations}

${ }^{1}$ Department of Medicine, College of Medicine, University of Saskatchewan, Saskatoon, Saskatchewan, Canada

${ }^{2}$ School of Nursing, Saskatchewan Polytechnic, Saskatoon, Saskatchewan, Canada ${ }^{3}$ College of Education, University of Saskatchewan, Saskatoon, Saskatchewan,

Canada

${ }^{4}$ School of Rehabilitation Science, University of Saskatchewan, Saskatoon, Saskatchewan, Canada

${ }^{5}$ Healthcare Quality Programs, Queen's University, Kingston, Ontario, Canada ${ }^{6}$ Leslie and Irene Dube Health Sciences Library, University of Saskatchewan, Saskatoon, Saskatchewan, Canada

${ }^{7}$ Department of Community Health and Epidemiology, University of Saskatchewan, Saskatoon, Saskatchewan, Canada

${ }^{8}$ Medicine, University of Saskatchewan, Saskatoon, Saskatchewan, Canada

Contributors DG, EH, MS and TR conceptualised the study. EW conducted the literature search. DG coordinated the project and is the guarantor. MM, LN, MS, EH, TR, CH, EDP and DG screened the studies and contributed to the interpretation of findings. DG, MM and LN extracted the data. DG drafted and all authors critically reviewed and approved the revised manuscript.

Funding This work was supported by a Targeted Collaborated Innovation Grant \#3894 from the Saskatchewan Health Research Foundation.

Competing interests None declared.

Patient consent for publication Not required.

Provenance and peer review Not commissioned; externally peer reviewed.

Data sharing statement All publications cited in this journal are publicly available.
Open access This is an open access article distributed in accordance with the Creative Commons Attribution Non Commercial (CC BY-NC 4.0) license, which permits others to distribute, remix, adapt, build upon this work non-commercially, and license their derivative works on different terms, provided the original work is properly cited, appropriate credit is given, any changes made indicated, and the use is non-commercial. See: http://creativecommons.org/licenses/by-nc/4.0/.

\section{REFERENCES}

1. Groene O. Patient centredness and quality improvement efforts in hospitals: rationale, measurement, implementation. Int J Qual Health Care 2011;23:531-7.

2. Lombarts MJ, Rupp I, Vallejo P, et al. Application of quality improvement strategies in 389 European hospitals: results of the MARQulS project. Qual Saf Health Care 2009;18 Suppl 1(Suppl 1):i28-i37.

3. Carman KL, Dardess P, Maurer M, et al. Patient and family engagement: a framework for understanding the elements and developing interventions and policies. Health Aff 2013:32:223-31.

4. Clancy CM. Patient engagement in health care. Health Serv Res 2011;46:389-93.

5. World Health Organization. Patient Engagement: Technical Series on Safer Primary Care 2016. 2016. Available at http://apps.who. int/iris/bitstream/handle/10665/252269/9789241511629-eng.pdf; jsessionid=2D38D96403E594B7509C1F6079358A6A? sequence $=1$.

6. Hibbard JH, Mahoney ER, Stock R, et al. Do increases in patient activation result in improved self-management behaviors? Health Serv Res 2007;42:1443-63.

7. Mosen DM, Schmittdiel J, Hibbard J, et al. Is patient activation associated with outcomes of care for adults with chronic conditions? J Ambul Care Manage 2007;30:21-9.

8. Weingart SN, Zhu J, Chiappetta L, et al. Hospitalized patients' participation and its impact on quality of care and patient safety. International Journal for Quality in Health Care 2011;23:269-77.

9. Epstein RM, Franks P, Shields CG, et al. Patient-centered communication and diagnostic testing. Ann Fam Med 2005;3:415-21.

10. Bertakis KD, Azari R. Patient-centered care is associated with decreased health care utilization. J Am Board Fam Med 2011;24:229-39.

11. Charmel PA, Frampton SB. Building the business case for patientcentered care. Healthc Financ Manage 2008;62:80-5.

12. Aronson PL, Yau J, Helfaer MA, et al. Impact of family presence during pediatric intensive care unit rounds on the family and medical team. Pediatrics 2009;124:1119-25.

13. Balik B, Conway J, Zipperer L, et al. Achieving an exceptional patients and family experience of inpatient hospital care. IHI Innovation Series white paper. Cambridge: MASS: Institute for Healthcare Improvement, Elements of hospital-based patient- and family-centred care, 2011.

14. Gausvik C, Lautar A, Miller L, et al. Structured nursing communication on interdisciplinary acute care teams improves perceptions of safety, efficiency, understanding of care plans and team work as well as job satisfaction. J Multidisc Healthcare 2015;8:33

15. Batalden $\mathrm{M}$, Batalden $\mathrm{P}$, Margolis $\mathrm{P}$, et al. Coproduction of healthcare service. BMJ Qual Saf 2016;25:509-17.

16. Gagliardi AR, Légaré F, Brouwers MC, et al. Patient-mediated knowledge translation (PKT) interventions for clinical encounters: a systematic review. Implement Sci 2016;11:26.17.

17. Herrin J, Harris KG, Kenward K, et al. Patient and family engagement: a survey of US hospital practices. BMJ Qual Saf 2016;25:182-9.

18. Agency for Healthcare Research and Quality. National healthcare quality and disparities report and 5th anniversary update on the National Quality Strategy: Priorities of the National Quality Strategy. 2015. Available at https://www.ahrq.gov/research/findings/nhqrdr/ nhqdr15/priorities.html.

19. Michie S, Richardson M, Johnston M, et al. The behavior change technique taxonomy (v1) of 93 hierarchically clustered techniques: building an international consensus for the reporting of behavior change interventions. Ann Behav Med 2013;46:81-95.

20. National Institute for Health and Care Excellence (NICE). Behaviour change: individual approaches. 2014 https://www.nice.org.uk/ guidance/ph49/chapter/7-glossary.

21. Presseau J, Ivers NM, Newham JJ, et al. Using a behaviour change techniques taxonomy to identify active ingredients within trials of implementation interventions for diabetes care. Implement Sci 2015; $10: 55$ 
22. Arksey H, O'Malley L. Scoping studies: towards a methodological framework. Int J Soc Res Methodol 2005;8:19-32.

23. Goodridge D, Henry C, Watson E, et al. Structured approaches to promote patient and family engagement in treatment in acute care hospital settings: protocol for a systematic scoping review. Syst Rev 2018;7:35.

24. Colquhoun HL, Levac D, O'Brien KK, et al. Scoping reviews: time for clarity in definition, methods, and reporting. $J$ Clin Epidemiol 2014;67:1291-4.

25. Levac D, Colquhoun H, O'Brien KK. Scoping studies: advancing the methodology. Implement Sci 2010;5:69.

26. Daudt HM, van Mossel C, Scott SJ. Enhancing the scoping study methodology: a large, inter-professional team's experience with Arksey and O'Malley's framework. BMC Med Res Methodol 2013;13:48.

27. Tricco AC, Lillie E, Zarin W, et al. PRISMA Extension for Scoping Reviews (PRISMA-ScR): Checklist and Explanation. Ann Intern Med 2018;169:467-73.

28. Staniszewska S, Brett J, Simera I, et al. GRIPP2 reporting checklists: tools to improve reporting of patient and public involvement in research. BMJ 2017;358:j3453.

29. Covidence systematic review software, Veritas Health Innovation. www.covidence.org.

30. Anthony R, Miranda F, Mawji Z, et al. John M. Eisenberg Patient Safety Awards. The LVHHN patient safety video: patients as partners in safe care delivery. Jt Comm J Qual Saf 2003;29:640-5.

31. Ayana M, Pound P, Ebrahim S. The views of therapists on the use of a patient-held record in the care of stroke patients. Clin Rehabil 1998;12:328-37.

32. Baird SK, Turbin LB. Condition concern: an innovative response system for enhancing hospitalized patient care and safety. J Nurs Care Qual 2011;26:199-207.

33. Baysari MT, Adams K, Lehnbom EC, et al. iPad use at the bedside: a tool for engaging patients in care processes during ward rounds? Intern Med J 2014;44:986-90.

34. Berger JL. Incorporation of the Tidal Model into the interdisciplinary plan of care--a program quality improvement project. J Psychiatr Ment Health Nurs 2006;13:464-7.

35. Black P, Boore JR, Parahoo K. The effect of nurse-facilitated family participation in the psychological care of the critically ill patient. $J$ Adv Nurs 2011;67:1091-101.

36. Boltz M, Chippendale T, Resnick B, et al. Testing family-centered, function-focused care in hospitalized persons with dementia. Neurodegener Dis Manag 2015;5:203-15.

37. Bradley S, Mott S. Adopting a patient-centred approach: an investigation into the introduction of bedside handover to three rural hospitals. J Clin Nurs 2014;23:1927-36.

38. Bull MJ, Hansen HE, Gross CR. A professional-patient partnership model of discharge planning with elders hospitalized with heart failure. Appl Nurs Res 2000;13:19-28.

39. Werumeus Buning A, Klopotowska JE, Duyvendak M, et al. Patient empowerment through provision of a mobile application for medication reconciliation: a proof of concept study. BMJ Innov 2016;2:152-7.

40. Coleman EA, Parry C, Chalmers S, et al. The care transitions intervention: results of a randomized controlled trial. Arch Int Med 2006;166:1822-8.

41. Coleman EA, Smith JD, Frank JC, et al. Preparing patients and caregivers to participate in care delivered across settings: the Care Transitions Intervention. J Am Geriatr Soc 2004;52:1817-25.

42. Cook DJ, Manning DM, Holland DE, et al. Patient engagement and reported outcomes in surgical recovery: effectiveness of an e-health platform. J Am Coll Surg 2013;217:648-55.

43. Cordasco KM, Asch SM, Bell DS, et al. A low-literacy medication education tool for safety-net hospital patients. Am J Prev Med 2009;37:S209-S216.

44. Dalal AK, Dykes PC, Collins S, et al. A web-based, patient-centered toolkit to engage patients and caregivers in the acute care setting: a preliminary evaluation. J Am Med Inform Assoc 2016;23:80-7.

45. Dalton C, Farrell R, De Souza A, et al. Patient inclusion in goal setting during early inpatient rehabilitation after acquired brain injury. Clin Rehabil 2012;26:165-73.

46. Davis RE, Pinto A, Sevdalis N, et al. Patients' and health care professionals' attitudes towards the PINK patient safety video. $J$ Eval Clin Pract 2012;18:848-53.

47. Davis RE, Sevdalis N, Pinto A, et al. Patients' attitudes towards patient involvement in safety interventions: results of two exploratory studies. Health Expect 2013;16:e164-e176.

48. D'Cruz K, Unsworth C, Roberts K, et al. Engaging patients with moderate to severe acquired brain injury in goal setting. Int $J$ Ther Rehabil 2016;23:20-31.
49. Dev R, Coulson L, Del Fabbro E, et al. A prospective study of family conferences: effects of patient presence on emotional expression and end-of-life discussions. J Pain Symptom Manage 2013:46:536-45.

50. Dijkstra R, Braspenning J, Grol R. Empowering patients: how to implement a diabetes passport in hospital care. Patient Educ Couns 2002;47:173-7.

51. Donnelly SM, Carter-Anad J, Cahill S, et al. Multiprofessional views on older patients' participating in care planning meetings in a hospital context. Practice Soc Work Act 2013;25:121-38.

52. Doyle CJ, Post H, Burney RE, et al. Family participation during resuscitation: an option. Ann Emerg Med 1987;16:673-5.

53. Duckworth M, Leung E, Fuller T, et al. Nurse, Patient, and Care Partner Perceptions of a Personalized Safety Plan Screensaver. $J$ Gerontol Nurs 2017;43:15-22.

54. Duncan C. An exploratory study of patient's feelings about asking healthcare professionals to wash their hands. J Ren Care 2007;33:30-4.

55. Dykes PC, Rozenblum R, Dalal A, et al. Prospective Evaluation of a Multifaceted Intervention to Improve Outcomes in Intensive Care: The Promoting Respect and Ongoing Safety Through Patient Engagement Communication and Technology Study. Crit Care Med 2017;45:e806-e813.

56. Dykes PC, Stade D, Chang F, et al. Participatory Design and Development of a Patient-centered Toolkit to Engage Hospitalized Patients and Care Partners in their Plan of Care. AMIA Annu Symp Proc 2014;2014:486-95.

57. Dyrstad DN, Storm M. Interprofessional simulation to improve patient participation in transitional care. Scand J Caring Sci 2017;31:273-84.

58. Ellegaard T, Bliksted V, Lomborg K, et al. Use of patient-controlled psychiatric hospital admissions: patients' perspective. Nord $J$ Psychiatry 2017;71:370-7.

59. Ewart L, Moore J, Gibbs C, et al. Patient- and family-centred care on an acute adult cardiac ward. Br J Nurs 2014;23:213-8.

60. Fredericks JE, Bunting RF. Implementation of a patient-friendly medication schedule to improve patient safety within a healthcare system. J Healthc Risk Manag 2010;29:22-7.

61. Furness ND, Bradford OJ, Paterson MP. Tablets in trauma: using mobile computing platforms to improve patient understanding and experience. Orthopedics 2013;36:205-8.

62. Gillespie BM, Chaboyer W, Sykes M, et al. Development and pilot testing of a patient-participatory pressure ulcer prevention care bundle. J Nurs Care Qual 2014;29:74-82.

63. Gill SD, Redden-Hoare J, Dunning TL, et al. Health services should collect feedback from inpatients at the point of service: opinions from patients and staff in acute and subacute facilities. Int J Qual Health Care 2015;27:507-12.

64. Gillis C, Gill M, Marlett N, et al. Patients as partners in Enhanced Recovery After Surgery: A qualitative patient-led study. BMJ Open 2017;7:e017002.

65. Greenhouse PK, Kuzminsky B, Martin SC, et al. Emergency calling a condition $\mathrm{h}(\mathrm{elp})$ : one facility gives patients and families the ability to summon a rapid response team. Am J Nurs 2006;106:63-6.

66. Greysen SR, Khanna RR, Jacolbia R, et al. Tablet computers for hospitalized patients: a pilot study to improve inpatient engagement. J Hosp Med 2014;9:396-9.

67. Grieco AJ, Garnett SA, Glassman KS, et al. New York University Medical Center's Cooperative Care Unit: patient education and family participation during hospitalization--the first ten years. Patient Educ Couns 1990:15:3-15.

68. Hamann J, Mendel R, Meier A, et al. "How to speak to your psychiatrist": shared decision-making training for inpatients with schizophrenia. Psychiatr Serv 2011;62:1218-21.

69. Hill AM, McPhail SM, Francis-Coad J, et al. Educators' perspectives about how older hospital patients can engage in a falls prevention education programme: a qualitative process evaluation. BMJ Open 2015;5:e009780.

70. Hirano Y, Maeshima S, Osawa A, et al. The effect of voluntary training with family participation on early home discharge in patients with severe stroke at a convalescent rehabilitation ward. Eur Neurol 2012;68:221-8

71. Huffines M, Johnson KL, Smitz Naranjo LL, et al. Improving Family Satisfaction and Participation in Decision Making in an Intensive Care Unit. Crit Care Nurse 2013;33:56-69.

72. Ivarsson $B$, Larsson $S$, Lührs $C$, et al. Extended written preoperative information about possible complications at cardiac surgery--do the patients want to know? Eur J Cardiothorac Surg 2005;28:407-14. 
73. Jacobowski NL, Girard TD, Mulder JA, et al. Communication in critical care: family rounds in the intensive care unit. Am J Crit Care 2010;19:421-30.

74. Jangland E, Carlsson M, Lundgren E, et al. The impact of an intervention to improve patient participation in a surgical care unit: quasi-experimental study. Int J Nurs Stud 2012;49:528-38.

75. Jangland E, Gunningberg L. Improving patient participation in a challenging context: a 2-year evaluation study of an implementation project. J Nurs Manag 2017;25:266-75.

76. Jeffs L, Beswick S, Acott A, et al. Patients' views on bedside nursing handover: creating a space to connect. J Nurs Care Qual 2014;29:149-54.

77. Kutty S, Weil S. "Your Health Care--Be Involved": the evaluation of a provincial patient afety tips initiative. Healthc Q 2006;9:102-7.

78. Laitinen-Junkkari $P$, Meriläinen $P$, Sinkkonen S. Informal caregivers' participation in elderly-patient care: an interrupted time-series study. Int J Nurs Pract 2001;7:199-213.

79. Lakeman R. Practice standards to improve the quality of family and carer participation in adult mental health care: an overview and evaluation. Int J Ment Health Nurs 2008;17:44-56.

80. Langer T, Martinez W, Browning D, et al. Patients as teachers in patient safety: a new interprofessional educational model for collaborative learning about medical error disclosure and prevention. J Gen Int Med 2015;30:S504

81. Lankarani-Fard A, Knapp $\mathrm{H}$, Lorenz KA, et al. Feasibility of discussing end-of-life care goals with inpatients using a structured, conversational approach: the go wish card game. J Pain Symptom Manage 2010;39:637-43.

82. Lawton R, O'Hara JK, Sheard L, et al. Can patient involvement improve patient safety? A cluster randomised control trial of the Patient Reporting and Action for a Safe Environment (PRASE) intervention. BMJ Qual Saf 2017;26:622-31.

83. Lean M, Leavey G, Killaspy $\mathrm{H}$, et al. Barriers to the sustainability of an intervention designed to improve patient engagement within NHS mental health rehabilitation units: a qualitative study nested within a randomised controlled trial. BMC Psychiatry 2015;15:209.

84. Lent V, Eckstein EC, Cameron AS, et al. Evaluation of patient participation in a patient empowerment initiative to improve hand hygiene practices in a Veterans Affairs medical center. Am J Infect Control 2009;37:117-20.

85. Leske JS, McAndrew NS, Brasel KJ, et al. Family Presence During Resuscitation After Trauma. J Trauma Nurs 2017;24:85-96.

86. Lindberg $\mathrm{E}$, Persson $\mathrm{E}, \mathrm{Hörberg} U$, et al. Older patients participation in team meetings-a phenomenological study from the nurses' perspective. Int J Qual Stud Health Well-being 2013;8:21908

87. Livingston JD, Nijdam-Jones A, Lapsley S, et al. Supporting recovery by improving patient engagement in a forensic mental health hospital: results from a demonstration project. $J \mathrm{Am}$ Psychiatr Nurs Assoc 2013;19:132-45.

88. Louch G, O'Hara J, Mohammed MA. A qualitative formative evaluation of a patient-centred patient safety intervention delivered in collaboration with hospital volunteers. Health Expect 2017;20:1143-53.

89. Martínez-Velilla N, Garrués-Irisarri M, Ibañez-Beroiz B, et al. An exercise program with patient's involvement and family support can modify the cognitive and affective trajectory of acutely hospitalized older medical patients: a pilot study. Aging Clin Exp Res 2016;28:483-90.

90. McGuckin M, Waterman R, Storr IJ, et al. Evaluation of a patientempowering hand hygiene programme in the UK. J Hosp Infect 2001;48:222-7.

91. McMurray A, Chaboyer W, Wallis M, et al. Patients' perspectives of bedside nursing handover. Collegian 2011;18:19-26.

92. Nyborg I, Kvigne K, Danbolt LJ, et al. Ambiguous participation in older hospitalized patients: gaining influence through active and passive approaches-a qualitative study. BMC Nurs 2016;15:50.

93. Odell M, Gerber K, Gager M. Call 4 Concern: patient and relative activated critical care outreach. Br J Nurs 2010;19:1390-5.

94. O'Leary KJ, Lohman ME, Culver E, et al. The effect of tablet computers with a mobile patient portal application on hospitalized patients' knowledge and activation. J Am Med Inform Assoc 2016;23:159-65.

95. Olsø TM, Gudde CB, Moljord IE, et al. More than just a bed: mental health service users' experiences of self-referral admission. Int J Ment Health Syst 2016;10.

96. Paradis E, Leslie M, Gropper MA. Interprofessional rhetoric and operational realities: an ethnographic study of rounds in four intensive care units. Adv Health Sci Educ Theory Pract 2016;21:735-48
97. Pegg PO, Auerbach SM, Seel RT, et al. The Impact of PatientCentered Information on Patients' Treatment Satisfaction and Outcomes in Traumatic Brain Injury Rehabilitation. Rehabil Psychol 2005;50:366-74.

98. Pinto A, Vincent C, Darzi A, et al. A qualitative exploration of patients' attitudes towards the 'Participate Inform Notice Know' (PINK) patient safety video. Int J Qual Health Care 2013;25:29-34.

99. Pomey MP, Ghadiri DP, Karazivan P, et al. Patients as partners: a qualitative study of patients' engagement in their health care. PLoS One 2015;10:e0122499.

100. Rise MB, Grimstad H, Solbjør M, et al. Effect of an institutional development plan for user participation on professionals knowledge, practice, and attitudes. A controlled study. BMC Health Serv Res 2011;11:296.

101. Rise MB, Steinsbekk A. Does implementing a development plan for user participation in a mental hospital change patients' experience? A non-randomized controlled study. Health Expect 2015;18:809-25.

102. Rotman-Pikielny $P$, Rabin B, Amoyal S, et al. Participation of family members in ward rounds: Attitude of medical staff, patients and relatives. Patient Educ Couns 2007;65:166-70.

103. Ruland CM. Decision support for patient preference-based care planning: effects on nursing care and patient outcomes. J Am Med Inform Assoc 1999;6:304-12.

104. Ruland CM. Clinicians' use of a palm-top based system to elicit patient preferences at the bedside: a feasible technique to improve patient outcomes. Proc AMIA Symp 2000:739-43.

105. Sand-Jecklin K, Sherman J. Incorporating bedside report into nursing handoff: evaluation of change in practice. J Nurs Care Qual 2013;28:186-94.

106. See MT, Chan WC, Huggan PJ, et al. Effectiveness of a patient education intervention in enhancing the self-efficacy of hospitalized patients to recognize and report acute deteriorating conditions. Patient Educ Couns 2014;97:122-7.

107. Sehgal NL, Green A, Vidyarthi AR, et al. Patient whiteboards as a communication tool in the hospital setting: a survey of practices and recommendations. J Hosp Med 2010;5:234-9.

108. Shulkin D, O'Keefe T, Visconi D, et al. Eliminating visiting hour restrictions in hospitals. J Healthc Qual 2014;36:54-7.

109. Skolasky RL, Maggard AM, Li D, et al. Health behavior change counseling in surgery for degenerative lumbar spinal stenosis. Part II: patient activation mediates the effects of health behavior change counseling on rehabilitation engagement. Arch Phys Med Rehabil 2015;96:1208-14.

110. Stein EJ, Furedy RL, Simonton MJ, et al. Patient access to medical records on a psychiatric inpatient unit. Am J Psychiatry 1979;136:327-9.

111. Swenne CL, Skytt B. The ward round--patient experiences and barriers to participation. Scand J Caring Sci 2014;28:297-304.

112. Timonen L, Sihvonen M. Patient participation in bedside reporting on surgical wards. J Clin Nurs 2000;9:542-8.

113. Trummer UF, Mueller UO, Nowak $P$, et al. Does physician-patient communication that aims at empowering patients improve clinica outcome? A case study. Patient Educ Couns 2006;61:299-306.

114. Turner J, Gardner B, Staples T, et al. Medicines with respect (part two): Implementation and evaluation of a medication management initiative in acute in-patient settings. Ment Health Nurs 2008;28:12-15.

115. Van Gaal BGI, Schoonhoven L, Mintjes JAJ, et al. Fewer adverse events as a result of the SAFE or SORRY? Progamme in hospitals and nursing homes. Part i: primary outcome of a cluster randomized trial. Int J Nurs Stud 2011;49:1040-8.

116. Wressle E, Eeg-Olofsson A-M, Marcusson J, et al. Improved client participation in the rehabilitation process using a client-centred goal formulation structure. J Rehabil Med 2002;34:5-11.

117. Young CA, Manmathan GP, Ward JC. Perceptions of goal setting in a neurological rehabilitation unit: a qualitative study of patients, carers and staff. J Rehabil Med 2008;40:190-4.

118. Hollywood L, Surgenor D, Reicks M, et al. Identification of behavior change technique applied in interventions to improve cooking skills and food skills among adults. Crit Rev Food Sci Nutr 2017;58:1-14.

119. Kahwati L, Viswanathan M, Golin CE, et al. Identifying configurations of behavior change techniques in effective medication adherence interventions: a qualitative comparative analysis. Syst Rev 2016;5:83.

120. Soltani H, Arden MA, Duxbury AMS, et al. An Analysis of Behaviour Change Techniques Used in a Sample of Gestational Weight Management Trials. J Pregnancy 2016;2016:1-15.

121. Goodridge D, Isinger T, Rotter T. Patient family advisors perspectives on engagement in health-care quality improvement initiatives: Power and partnership. Health Expect 2018;21:379-86. 